\title{
Editorial
}

\section{Desarrollo infantil temprano...Un desafío}

\author{
LIDYA TELLERÍAS C. ${ }^{1}$, HELIA MOLINA M. ${ }^{2}$ \\ 1. Pediatra. Presidenta, Sociedad Chilena de Pediatría. \\ 2. Pediatra. Jefe de División de Políticas Públicas Saludables y Promoción, Ministerio de Salud de Chile.
}

\section{TIERRA CHILENA Gabriela Mistral}

Danzamos en tierra chilena, más bella que Lía y Raquel; la tierra que amasa a los hombres de labios y pecho sin hiel...

La tierra más verde de huertos, la tierra más rubia de mies, la tierra más roja de viñas, iqué dulce que roza los pies!

Su polvo hizo nuestras mejillas, su río hizo nuestro reír, $y$ besa los pies de la ronda que la hace cual madre gemir.

Es bella, y por bella queremos sus pastos de rondas albear; es libre y por libre deseamos su rostro de cantos bañar...

Mañana abriremos sus rocas, la haremos viñedo y pomar; mañana alzaremos sus pueblos; ¡hoy sólo queremos danzar!
Para la Vida (UNICEF)

Los niños comienzan a aprender desde que nacen. Crecen y aprenden más rápidamente cuando reciben atención, afecto y estímulos, además de una buena nutrición y una atención de la salud adecuada. Alentar a los niños a observar y expresarse por su cuenta, a jugar y a explorar, les ayuda en su aprendizaje y en su desarrollo social, fisico e intelectual.

La Sociedad Chilena de Pediatria, es una Sociedad Científica que tiene los siguientes objetivos:

Uno. Contribuir a elevar el nivel científico y técnico de los profesionales vinculados a la Pediatría.

Dos. Asesorar y/o colaborar con los diversos organismos nacionales que tengan responsabilidades en los problemas de la salud física y psíquica del niño y adolescente.

Tres. Divulgar los conocimientos pediátricos.

Chile Crece Contigo es un sistema de Protección Social Integral a la primera Infancia que tiene como misión acompañar, proteger y

Correspondencia a:

Lidya Tellerías C.

E-mail: Itellerias@yahoo.com 
apoyar integralmente, a todos los niños, niñas y sus familias, a través de acciones y servicios de carácter universal e intersectorial, focalizando apoyos especiales a aquellos que representan el $40 \%$ mas vulnerable y aquellos con necesidades especiales.

El desarrollo cerebral en la infancia temprana es un factor determinante de la salud, aprendizaje y conducta a lo largo de toda la vida; por ello la Sociedad Chilena de Pediatría, cumpliendo con sus objetivos y en alianza con Programa Chile Crece Contigo, han preparado este suplemento de la Revista Chilena de Pediatría, dedicado al desarrollo infantil temprano, un desafío para los pediatras, ya que la finalidad del programa es la protección, por tanto la promoción del desarrollo temprano, detección precoz de las alteraciones y su manejo adecuado.

El suplemento no pretende ser un compendio que abarque la totalidad de los temas asociados al desarrollo integral en la infancia pero se han seleccionado aquéllos tópicos que representan el mayor desafío de abordaje desde la pediatría.

Los temas tratados por cada uno de los autores, quienes generosa y desinteresadamente nos regalan su experiencia tiene como objetivo orientar a los profesionales de salud, en particular a los médicos generales y pediatras a enfrentar precozmente a niños con alguna dificultad y derivar en el momento oportuno así como también entregar una revisión actualizada del contexto mundial de las políticas públicas para el desarrollo integral de la infancia.

Se revisan los conceptos de desarrollo glo- bal de las personas y neurodesarrollo como bases para emitir un juicio y sugerencias sobre el rol del Pediatra en esta área.

\section{Debemos preguntarnos:}

¿Evaluamos los pediatras el desarrollo biosicosocial o sólo sicomotor?

¿Qué instrumentos usamos para ello?

¿Qué importancia le damos?

¿Sabemos abordar el tema en forma integral reconociendo los determinantes distales y proximales?

Hemos relevado el aspecto ético, fundamental en nuestro trabajo permanente. Violencia en la familia, el impacto de los tóxicos ambientales, enfermedades metabólicas, programas de screening neonatal entre otros

Quisimos abarcar aquellos tópicos relacionados con el desarrollo integral y armónico del niño.

El desarrollo, aun siendo un proceso universal, tiene rasgos propios de cada país o región debido a interacción de elementos ambientales y genéticos, propios de cada cultura en particular.

La inversión realizada en la infancia tiene un alto retorno social y económico los pediatras somos actores relevantes para el logro de que los niñas y niños chilenos puedan lograr su optimo potencial genetico de desarrollo sin importar su condicon economica etnica o geográfica.

El impacto de este gran esfuerzo país lo veremos reflejado en el futuro. 